6 British Thoracic Society Research Committee. Short course chemotherapy for lymph node tuberculosis: final report at 5 vears. $\mathrm{Br} 7$ Dis Chest 1988:82: $282-4$

McCarthy OR, Rudd RM. Six month chemotherapy for lymph node tuberculosis. Respiratory Medicine 1989;83:425-7.

8 Gillam PMS, Knowles JP. The treatment of tuberculous lymphadenitis Tubercle 1963;44:112-8.

9 Campbell IA, Dyson AJ. Lymph node tuberculosis: a comparison of various methods of treatment. Tubercle 1977;58:171-9.

10 Campbell IA, Dyson AJ. Lymph node tuberculosis: a comparison of treatments 18 months after completion of chemotherapy. Tubercle 1979;60 95-8.

11 Mitchison DA, Allen BW, Devi Manickavasagar. Selective Kirchner medium in the culture of specimens other than sputum for mycobacteria. F Clin Pathol 1983:36:1357-61.

12 Canetti G, Fox W, Khomenko R, et al. Advances in the techniques of testing mycobacterial drug sensitivity and the use of sensitivity tests in tuberculosis control programmes. Bull WHO 1969;41:21-43.

13 Pamra SP, Mathur GP. A co-operative study of tuberculous cervical lymphadenitis. Indian f Med Res 1974;62:1631-46.

14 Kulkarni KG. Bacteriological study of tuberculous lymphadenitis. Indian foumal of Tuberculosis 1974;21:60-84.

15 Anonymous. Paradoxical responses during the chemotherapy of tuberculosis [Editorial]. F Infect 1987;15:1-3.

(Accepted 13 fune 1990)

\title{
Symptoms of low blood pressure: a population study
}

\author{
Simon Wessely, Judith Nickson, Brian Cox
}

\begin{abstract}
Objective-To establish whether an association exists between blood pressures in the "low normal" range and common symptoms such as tiredness, dizziness, headache, and palpitation, as suggested by French and German medical practice but not English or American medical practice.
\end{abstract}

Design-Cross sectional population based survey (the health and lifestyle survey) of blood pressure measurements and self reported common symptoms. Results were analysed by combined stratification and logistic regression.

Subjects-7383 (82\%) Adults aged 18 and over chosen from the electoral register in England, Wales, and Scotland for the health and lifestyle survey, in whom satisfactory physiological measurements were taken, from 9003 in the interviewed sample.

Main outcome measures-Body mass index, smoking, social class, exercise, self declared physical illnesses, hours slept, use of drugs, and psychological illness as determined with the general health questionnaire assessed as potential confounders.

Results-True confounders were sex, age, taking of drugs, physical illness, exercise, and body mass index. A negative association was found between systolic blood pressure and self reported tiredness and feeling faint, which persisted after adjustment for the confounders. The association was strongest in women aged under 50 . A negative association between systolic blood pressure and headache and a positive association between systolic blood pressure and palpitation were explained by confounding by age.

Conclusions-Systemic hypotension is associated with persistent tiredness but treatment is not suggested as either possible or necessary. Instead, low blood pressures may be associated with opposite effects on mortality contrasted with morbidity.

\section{London SE5 8AF}

Simon Wessely, MRCPSYCH, research fellow

\section{Office of the Regius Professor of Physic, University of Cambridge Clinical School, Cambridge Judith Nickson, BA, research associate}

\section{Department of}

Community Medicine,

University of Cambridge, Cambridge

Brian Cox, PHD, lecturer in

community medicine

Correspondence to:

Dr Wessely. even in the English speaking world, large numbers of people receive treatment for low blood pressure; one Canadian survey found that nearly a tenth of a community sample was receiving treatment for "low blood pressure."

What is the evidence? At the beginning of this century most authorities assumed that low blood pressure was associated with several so called "neurasthenic" symptoms, such as tiredness, weakness, fainting, and dizziness, ${ }^{67}$ although the same symptoms were also attributed to high blood pressure. ${ }^{8}$ However, scepticism increased, culminating in Robinson's definitive article on the topic in $1940 .{ }^{9} \mathrm{He}$ vehemently attacked those who regarded low blood pressure as pathological and presented data showing that low blood pressure was associated with decreased mortality. He continued, "the symptoms usually ascribed to hypotension are in reality commoner among hypertensive persons. There are no symptoms peculiar to low blood pressure." This rapidly became the new conventional wisdom. A leading text now states: "Most persons with systolic pressures in the range of 90 to $110 \mathrm{~mm} \mathrm{Hg}$ are normal and may actually have a greater life expectancy than those with 'normal' pressures."10 Although the evidence is, however, unequivocal that low blood pressure is associated with decreased mortality ${ }^{11}$ (the exception being the association between very low pressures and increased mortality in subjects with ischaemic heart disease, the so called $\mathrm{J}$ curve relation ${ }^{12}$ ), few data on the morbidity of low blood pressure exist. For example, although discussing mortality and morbidity, Robinson presented data only on mortality. ${ }^{9}$

Pemberton's analyses on data from an Australian survey, which disclosed a relation between tiredness and low blood pressure in women, ' reopened the debate. The relation did not extend to either dizziness or fainting, symptoms also traditionally associated with low blood pressure, whereas palpitations showed an opposite trend, being more common with higher blood pressures. Pemberton could quote only crude rates. Blood pressure and tiredness are influenced by many variables so it is necessary to determine whether his findings may not only be replicated but also be explained by confounding. We present an analysis of data from the health and lifestyle survey, ${ }^{13}$ which provides an opportunity to answer these questions.

\section{Methods}

\section{HEALTH AND LIFESTYLE SURVEY}

The health and lifestyle survey is the most comprehensive population based health survey carried out in Britain to date. The sampling frame for the survey was the entire adult population of England, Wales, and Scotland aged 18 and over. Preliminary selection was 
made randomly from the electoral register. Further selection was made using probability proportional to the size of the constituency, and then to that of the ward. The result was a sample of 12254 addresses, for which 9003 interviews were conducted, giving a nonresponse rate of $26 \cdot 5 \%$, mostly due to refusals. A high proportion of those interviewed $(82 \cdot 4 \%)$ consented to a follow up visit from a research nurse, at which time various physiological measurements were carried out, including blood pressure measurement. In 7383 people satisfactory measurements were taken, representing $82 \%$ of the interviewed sample or $60 \cdot 2 \%$ of the entire sampling frame. Finally, respondents were asked to complete the 30 item general health questionnaire ${ }^{14}$ and return it in a self addressed envelope. A total of 7304 participants accepted the questionnaire, and 6317 completed questionnaires were returned, representing $86.4 \%$ of those given the questionnaire or $70.2 \%$ of the entire sample.

The sample was compared with that of the 1981 census; owing to differences in availability for interview there was a slight excess of women, especially elderly women. ${ }^{15}$ Compared with other census data there was a slight underrepresentation of both single and divorced or separated women. It has been concluded, however, that "these sources of bias are small and the study appears to offer a good and representative sample of the population."

\section{MEASUREMENTS}

Blood pressure was measured by taking four measurements on a single occasion with the subject seated in an upright chair. A Datascope "Accutorr," set up to deflate and inflate the cuff automatically at one minute intervals, was used. Values were obtained by oscillometry and displayed digitally. The dependent variable was taken as the lowest observed value for systolic pressure. No differences were, however, obtained when the dependent variable was either mean systolic pressure or mean diastolic pressure.

Symptoms-A set list of 16 somatic symptoms were recorded by the interviewer during the semistructured interview. Fatigue was measured by the response to a single question: "Within the last month have you suffered from any problems with always feeling tired?" Other symptoms were recorded similarly.

TABLE I-Relation between systolic blood pressure and principal confounders (means)

\begin{tabular}{lccc}
\hline $\begin{array}{l}\text { Systolic blood } \\
\text { pressure } \\
(\mathrm{mm} \mathrm{Hg})\end{array}$ & $\begin{array}{c}\text { General } \\
\text { health } \\
\text { questionnaire }\end{array}$ & $\begin{array}{c}\text { Body mass index } \\
(\text { weight }(\mathrm{kg}) / \\
(\text { height }(\mathrm{m}))^{2}\end{array}$ & $\begin{array}{c}\text { Age } \\
\text { (years) }\end{array}$ \\
\hline$<100$ & $9 \cdot 63$ & $22 \cdot 03$ & $35 \cdot 51$ \\
$100-109$ & $9 \cdot 90$ & $22 \cdot 68$ & $36 \cdot 13$ \\
$110-119$ & $9 \cdot 39$ & $23 \cdot 76$ & $39 \cdot 12$ \\
$120-129$ & $9 \cdot 08$ & $24 \cdot 62$ & $43 \cdot 06$ \\
$130-139$ & $9 \cdot 54$ & $25 \cdot 55$ & $49 \cdot 76$ \\
$140-149$ & $9 \cdot 61$ & $26 \cdot 09$ & $55 \cdot 90$ \\
$150-159$ & $9 \cdot 26$ & $26 \cdot 06$ & $59 \cdot 92$ \\
$\geqslant 160$ & $9 \cdot 17$ & $26 \cdot 76$ & $66 \cdot 09$ \\
\hline All & $9 \cdot 40$ & 24.54 & $45 \cdot 86$ \\
\hline
\end{tabular}

TABLE III-Relation between tiredness and systolic blood pressure when data stratified by sex. Figures are percentages (numbers)

\begin{tabular}{|c|c|c|c|c|}
\hline \multirow{2}{*}{$\begin{array}{l}\text { Systolic blood } \\
\text { pressure } \\
(\mathrm{mm} \mathrm{Hg})\end{array}$} & \multicolumn{2}{|c|}{ Always tired } & \multicolumn{2}{|c|}{ Fainting and dizziness } \\
\hline & Men & Women & Men & Women \\
\hline$<100$ & $26 \cdot 1 \quad(12)$ & $41 \cdot 8(107)$ & $8 \cdot 7 \quad(4)$ & $12 \cdot 8(33)$ \\
\hline $100-109$ & 25.9 & $37 \cdot 1(286)$ & $6 \cdot 2(15)$ & $8.9(69)$ \\
\hline $110-119$ & $22 \cdot 3(146)$ & $28 \cdot 3(294)$ & $6.4(42)$ & $7 \cdot 5(78)$ \\
\hline $120-129$ & $18 \cdot 0(174)$ & $29 \cdot 1(242)$ & $3 \cdot 6(35)$ & $6.9(57)$ \\
\hline $130-139$ & $17 \cdot 5(112)$ & $31 \cdot 2(159)$ & $3 \cdot 7(24)$ & $10 \cdot 0(51)$ \\
\hline $140-149$ & $21 \cdot 1 \quad(84)$ & $25 \cdot 0$ & $6 \cdot 3(25)$ & $7 \cdot 9(23)$ \\
\hline $150-159$ & 14.9 (27) & $24.8 \quad(41)$ & $5 \cdot 5(10)$ & 14.0 \\
\hline$\geqslant 160$ & $17 \cdot 1 \quad(30)$ & $21 \cdot 4(47)$ & $4 \cdot 0$ & $11 \cdot 8(33)$ \\
\hline Total & $19 \cdot 6(648)$ & $30 \cdot 6(1249)$ & $4.9(162)$ & $8 \cdot 8(367)$ \\
\hline Test for trend & $\begin{array}{c}8.23 \\
\mathrm{p}=0.004\end{array}$ & $\begin{array}{c}33.18 \\
\mathrm{p}<0.001\end{array}$ & $\begin{array}{c}1 \cdot 15 \\
p=0.283\end{array}$ & $\begin{array}{c}1.02 \\
p=0.311\end{array}$ \\
\hline
\end{tabular}

Psychological illness was assessed by the general health questionnaire 30 , which was chosen as it is fairly free of somatic symptoms that may be present in both physical and psychological disorders. Particularly relevant to this analysis was that there is no question on fatigue. The questionnaire may be used in several ways to obtain data on the psychological health of a population. Recently a revised system of scoring has been devised as more appropriate for prevalence studies in which many respondents have chronic illness. ${ }^{16}$ In the health and lifestyle survey data set the revised method of scoring gives a more normal distribution of psychological morbidity than previous scoring methods. ${ }^{17}$ This may also be used as a dichotomous variable. A cut off point between 12 and 13 has been suggested for identifying probable psychiatric "caseness." 1617 Both methods of scoring were used in the study.

Body mass index was calculated according to the formula: weight $(\mathrm{kg}) /(\text { height }(\mathrm{m}))^{2}$.

Exercise-A composite variable representing the amount of time each respondent had spent in any form of physical exercise during the previous 14 days was created and divided into four categories of activity: 0 , nil or very low; 1 , low or moderate; 2 , moderate or active; and 3 , high.

Social class was taken from the registrar general's socioeconomic groupings. Three categories were used: classes I and II, III, and IV and V.

Other variables-Other important variables, such as taking of drugs (including antihypertensive agents) and current smoking, were assessed as part of the interview and were coded as present or absent. The subjects were also asked about the presence of any known physical illness, which was coded according to a checklist comprising 31 categories. Finally, the number of hours slept was divided into three categories. Subjects who admitted to sleeping for less than seven hours were categorised as low sleepers, between seven and nine hours as normal sleepers, and more than nine as high sleepers.

Data analysis and control of confounders-Potential confounders were identified in the complete data set

TABLE II - Relation between systolic blood pressure and principal confounders (proportions)

\begin{tabular}{|c|c|c|c|c|c|c|c|c|c|}
\hline $\begin{array}{l}\text { Systolic blood } \\
\text { pressure } \\
(\mathrm{mm} \mathrm{Hg})\end{array}$ & No & $\begin{array}{c}\text { \% Taking } \\
\text { drugs }\end{array}$ & $\%$ Women & $\begin{array}{l}\text { \% Physical } \\
\text { illness }\end{array}$ & $\%$ Smokers & $\begin{array}{l}\% \text { Nil or } \\
\text { very low } \\
\text { exercise }\end{array}$ & $\begin{array}{l}\text { \% In social } \\
\text { class } \\
\text { I or II }\end{array}$ & $\begin{array}{l}\% \text { With } \\
\text { low } \\
\text { sleep }\end{array}$ & $\begin{array}{l}\text { \% Psychiatric caseness } \\
\text { (from general health } \\
\text { questionnaire) }\end{array}$ \\
\hline$<100$ & 302 & $33 \cdot 8$ & $84 \cdot 7$ & $26 \cdot 2$ & $33 \cdot 7$ & $26 \cdot 2$ & $28 \cdot 8$ & $27 \cdot 2$ & $30 \cdot 2$ \\
\hline $100-109$ & 1014 & $28 \cdot 8$ & $87 \cdot 0$ & 21.8 & $34 \cdot 6$ & $25 \cdot 3$ & $29 \cdot 4$ & $30 \cdot 5$ & $33 \cdot 2$ \\
\hline $110-119$ & 1691 & $27 \cdot 5$ & $61 \cdot 4$ & $23 \cdot 8$ & $34 \cdot 7$ & $23 \cdot 6$ & $30 \cdot 0$ & $30 \cdot 3$ & 29.9 \\
\hline $120-129$ & 1795 & $29 \cdot 3$ & $48 \cdot 0$ & $28 \cdot 2$ & $34 \cdot 1$ & $27 \cdot 8$ & $29 \cdot 6$ & 34.9 & $27 \cdot 4$ \\
\hline $130-139$ & 1149 & $37 \cdot 1$ & $44 \cdot 3$ & 31.9 & $31 \cdot 2$ & $36 \cdot 6$ & $28 \cdot 1$ & $37 \cdot 4$ & $29 \cdot 5$ \\
\hline $140-149$ & 691 & $44 \cdot 6$ & $42 \cdot 3$ & $36 \cdot 7$ & $30 \cdot 0$ & $38 \cdot 6$ & $29 \cdot 2$ & $41 \cdot 3$ & $32 \cdot 2$ \\
\hline $150-159$ & 346 & $52 \cdot 0$ & $47 \cdot 7$ & $41 \cdot 0$ & 31.5 & $45 \cdot 3$ & $23 \cdot 7$ & $43 \cdot 2$ & $27 \cdot 6$ \\
\hline$\geqslant 160$ & 395 & $58 \cdot 7$ & $55 \cdot 7$ & $42 \cdot 0$ & $23 \cdot 8$ & $47 \cdot 8$ & $25 \cdot 4$ & $40 \cdot 6$ & $29 \cdot 7$ \\
\hline All & 7383 & $34 \cdot 3$ & $55 \cdot 3$ & $29 \cdot 0$ & $32 \cdot 8$ & $30 \cdot 7$ & $28 \cdot 8$ & $34 \cdot 6$ & $29 \cdot 7$ \\
\hline
\end{tabular}


(tables I, II). After stratification by sex (table III) adjustment was made for age and sex by the MantelHaenszel technique after tests for heterogeneity (tables IV, V). Finally, the fully adjusted effect of increasing blood pressure on the risk of being fatigued was calculated with logistic regression to control for the true confounders previously identified (table VI). Logistic regression uses the equation:

$$
\log (\mathrm{p} / \mathrm{l}-\mathrm{p})=\mathrm{m}+\mathrm{aX}+\mathrm{bY} \ldots
$$

where $p$ is the proportion of fatigued subjects; $m, a$, and $b$ are the parameters to be estimated and X, Y, etc, are the factors. These were entered as dummy variables $(0,1)$ for dichotomous variables (sex, taking of drugs, physical illness), factored variables with three categories (sleep, social class, and exercise), factored variables with five categories (age), and as a continuous variable (body mass index). A main effects model was used with no interaction terms. The logarithms of the odds were converted to odds ratios for ease of under-

TABLE IV-Relation between symptoms and systolic blood pressure adjusted for sex. Figures are odds ratios ( $95 \%$ confidence intervals)

\begin{tabular}{lllll}
\hline $\begin{array}{l}\text { Systolic blood } \\
\text { pressure }(\mathrm{mm} \mathrm{Hg})\end{array}$ & Always tired & Palpitations & Fainting and dizziness & Headache \\
\hline$<100$ & 1.00 & 1.00 & 1.00 & 1.00 \\
$100-109$ & $0.84(0.64$ to $1 \cdot 11)$ & $0.83(0.54$ to 1.27$)$ & $0.67(0.43$ to 1.03$)$ & $1.03(0.78$ to 1.36$)$ \\
$110-119$ & $0.58(0.45$ to 0.76$)$ & $1.00(0.67$ to 1.50$)$ & $0.57(0.38$ to 0.87$)$ & $0.92(0.70$ to 1.20$)$ \\
$120-129$ & $0.58(0.44$ to 0.76$)$ & $1.18(0.79$ to 1.78$)$ & $0.48(0.31$ to 0.75$)$ & $0.86(0.63$ to 1.09$)$ \\
$130-139$ & $0.63(0.47$ to 0.84$)$ & $1.93(1.30$ to 2.97$)$ & $0.70(0.44$ to $1 \cdot 10)$ & $0.83(0.61$ to 1.11$)$ \\
$140-149$ & $0.51(0.37$ to 0.72$)$ & $1.89(1.23$ to 3.02$)$ & $0.60(0.36$ to 1.02$)$ & $0.71(0.51$ to 0.98$)$ \\
$150-159$ & $0.47(0.32$ to 0.69$)$ & $2 \cdot 18(1.36$ to 3.61$)$ & $0.99(0.56$ to 1.74$)$ & $0.50(0.34$ to 0.74$)$ \\
$\geqslant 160$ & $0.41(0.29$ to 0.60$)$ & $2 \cdot 40(1.52$ to 3.83$)$ & $0.82(0.47$ to 1.41$)$ & $0.60(0.41$ to 0.86$)$ \\
Test for trend & $40.64, \mathrm{p}<0.001$ & $102.47, \mathrm{p}<0.001$ & $0.10, \mathrm{p}=0.756$ & $30.56, \mathrm{p}<0.001$ \\
\hline
\end{tabular}

TABLE V-Relation between symptoms and systolic blood pressure adjusted for sex and age. Figures are odds ratios ( $95 \%$ confidence intervals)

\begin{tabular}{|c|c|c|c|c|}
\hline $\begin{array}{l}\text { Systolic blood } \\
\text { pressure (mm Hg) }\end{array}$ & Always tired & Palpitations & Fainting and dizziness & Headache \\
\hline$<100$ & $1 \cdot 00$ & $1 \cdot 00$ & $1 \cdot 00$ & $1 \cdot 00$ \\
\hline $100-109$ & $0.84(0.62$ to 1.14$)$ & $0.83(0.55$ to 1.25$)$ & $0.85(0.64$ to 1.12$)$ & $1.05(0.80$ to 1.38$)$ \\
\hline $110-119$ & $0.59(0.44$ to 0.80$)$ & $0.87(0.59$ to 1.29$)$ & $0.59(0.45$ to 0.77$)$ & $0.98(0.76$ to 1.28$)$ \\
\hline $120-129$ & $0.59(0.44$ to 0.80$)$ & $0.84(0.57$ to 1.24$)$ & $0.61(0.45$ to 0.81$)$ & $0.96(0.73$ to 1.25$)$ \\
\hline $130-139$ & $0.62(0.45$ to 0.85$)$ & $1.00(0.67$ to 1.48$)$ & $0.65(0.46$ to 0.91$)$ & $0.98(0.74$ to 1.30$)$ \\
\hline $140-149$ & $0.55(0.38$ to 0.78$)$ & $0.86(0.56$ to 1.30$)$ & $0.67(0.44$ to 1.03$)$ & $0.91(0.67$ to 1.25$)$ \\
\hline $150-159$ & $0.45(0.29$ to 0.69$)$ & $0.97(0.62$ to 1.53$)$ & $0.43(0.24$ to 0.76$)$ & $0.77(0.53$ to 1.10$)$ \\
\hline$\geqslant 160$ & $0.44(0.29$ to 0.67$)$ & $0.89(0.57$ to 1.39$)$ & $0.47(0.23$ to 0.86$)$ & $0.93(0.65$ to 1.33$)$ \\
\hline Test for trend & $22 \cdot 64, \mathrm{p}<0.001$ & $0.39, p=0.532$ & $22.62, \mathrm{p}<0.001$ & $2 \cdot 38, p=0 \cdot 123$ \\
\hline
\end{tabular}

TABLE VI-Relation between tiredness and fainting or dizziness and systolic blood pressure adjusted for all identified confounders. ${ }^{\star}$ Figures are odds ratios ( $95 \%$ confidence intervals)

\begin{tabular}{|c|c|c|}
\hline $\begin{array}{l}\text { Systolic blood } \\
\text { pressure }(\mathrm{mm} \mathrm{Hg})\end{array}$ & Tiredness & Fainting or dizziness \\
\hline$<100$ & $1 \cdot 00$ & $1 \cdot 00$ \\
\hline $100-109$ & $0.85(0.64$ to 1.12$)$ & $0.73(0.46$ to 1.16$)$ \\
\hline $110-119$ & $0.65(0.49$ to 0.85$)$ & $0.68(0.44$ to 1.06$)$ \\
\hline $120-129$ & $0.61(0.46$ to 0.81$)$ & $0.48(0.30$ to 0.75$)$ \\
\hline $130-139$ & $0.62(0.46$ to 0.83$)$ & $0.52(0.32$ to 0.83$)$ \\
\hline $140-149$ & $0.61(0.44$ to 0.83$)$ & $0.51(0.30$ to 0.86$)$ \\
\hline $150-159$ & $0.49(0.33$ to 0.72$)$ & $0.60(0.34$ to 1.07$)$ \\
\hline$\geqslant 160$ & $0.46(0.31$ to 0.67$)$ & $0.45(0.26$ to 0.79$)$ \\
\hline
\end{tabular}

*Age, sex, social class, taking drugs, body mass index, sleep, physical illness, and physical activity.

TABLE VII - Effect of age on relation between systolic blood pressure and fainting and dizziness. Figures are percentages (numbers)

\begin{tabular}{lcccrr}
\hline $\begin{array}{l}\text { Systolic blood } \\
\text { pressure } \\
\text { (mm Hg) }\end{array}$ & $18-24$ & $25-34$ & $35-49$ & $50-64$ & $\geqslant 65$ \\
\cline { 2 - 6 } & $11 \cdot 2(30)$ & $7 \cdot 0(28)$ & $9 \cdot 0(38)$ & $10 \cdot 1(14)$ & $18 \cdot 0(11)$ \\
\hline 109 & $5 \cdot 9(32)$ & $5 \cdot 0(39)$ & $4 \cdot 5(54)$ & $5 \cdot 7(37)$ & $15 \cdot 9(50)$ \\
$110-129$ & $1.9(2)$ & $1 \cdot 8(4)$ & $5 \cdot 3(24)$ & $8 \cdot 6(52)$ & $9 \cdot 1(420)$ \\
$130-149$ & 0 & $4 \cdot 7(1)$ & $1 \cdot 5(1)$ & $6 \cdot 5(19)$ & $12 \cdot 6(45)$ \\
$\geqslant 150$ & $12 \cdot 77, \mathrm{p}<0.001$ & $5 \cdot 61, \mathrm{p}=0.018$ & $7 \cdot 46, \mathrm{p}=0.006$ & $0, \mathrm{p}=0.974$ & $2 \cdot 99, \mathrm{p}=0.084$ \\
Test for trend & $6.9(64)$ & $5 \cdot 0(72)$ & $5 \cdot 5(117)$ & $7 \cdot 2(122)$ & $12 \cdot 3(147)$ \\
\hline Total & & & &
\end{tabular}

\section{Discussion}

Contrary to our expectations, we showed a relation between tiredness and low blood pressure and thus confirmed the findings of Pemberton. ${ }^{.}$The association was also found for feeling faint or for dizziness; the lack of any such relation in Pemberton's crude data was because of the confounding effect of age. On the other hand, the unadjusted relation between systolic blood pressure and both palpitation and headache was 
explained by age and did not persist after appropriate adjustment. We conclude that both tiredness and feeling faint are associated with systolic pressures customarily regarded as beneficial in this country.

Might this be explained by limitations in method? To be able to explain the observed findings by nonresponse non-responders would have to differ from responders in both the exposure (systolic blood pressure) and the outcome (tiredness). No such differences were found whereas other differences, such as social class (data not shown), were controlled for in the subsequent analysis. A differential non-response on an unmeasured variable may never be excluded, but it is difficult to envisage any potential candidate variable that would differentially affect both blood pressure and tiredness. Observer bias is unlikely as the hypothesis under investigation was unknown to both the researchers and the respondents. Systematic bias in measuring blood pressure is also unlikely given the design of the study, and, even if present, it is implausible that it might have influenced the recording of fatigue. The effect was unlikely to be caused by subjects with low blood pressure being aware of the fact and thus developing symptoms ("labelling"). This is the explanation for the relation between hypertension and similar symptoms, ${ }^{20}{ }^{21}$ but there is no tradition in Britain of regarding low blood pressure as pathological, and any such effect would be accompanied by other symptoms of psychological illness. Finally, variables such as social class and treatment cover a hybrid of different factors, and grouping them together may hide important effects. Nevertheless, the strength of the observed association seems too large to be completely attributed to inadequate adjustment for confounders.

Thus we have shown an association between systolic blood pressure and fatigue. This linear trend is present at all pressures, suggesting a continuous distribution of risk without any threshold or cut off. There is no clear shortcoming in method to account for the observation. Nevertheless, there are several reasons for extreme caution before accepting that low blood pressure causes tiredness. Firstly, there is no clear pathophysiological explanation for this result. Most explanations of an alleged relation between symptoms and blood pressure in the population entail some link with autonomic arousal and hence between blood pressure, and psychosocial stress and "tension." Although such models are the basis of many lay explanations of hypertension, ${ }^{22}$ there is little empirical evidence for any link between psychological illness and blood pressure, ${ }^{2021}$ which was confirmed by this population study. Furthermore, an association would be in an opposite direction to that found here and might be expected to influence other symptoms, such as headache and anxiety. This was not found. Alternatively, the autoregulatory system, which serves to protect the cerebral circulation from the effects of both low and high blood pressures, ${ }^{23}$ may be at fault, but this remains speculative. Secondly, both tiredness and low blood pressure may be related to a third, unidentified common factor. For example, undiagnosed anaemia might still explain the association (adjustment could be made only for subjects who declared anaemia), but this is unlikely to be more than a partial explanation of the strength of the observed association. Although no obvious modern candidates, either inherited or acquired, exist for a common "low vitality" factor, such a concept would have been familiar to a previous generation of doctors. ${ }^{6}$ It would therefore be inappropriate to use the current findings to justify treatment of low blood pressure in individual subjects with symptoms. Observations concerning risk in populations cannot be extrapolated to "disease" in individual subjects. The danger of creating spurious illness categories and "non-diseases" is real. ${ }^{24}$ Instead, reviewing the evidence for the efficacy of treatment in those countries in which such treatment is already practised may be more worth while.

A more appropriate conclusion is to note the differences in the relation between blood pressure and mortality in contrast to that between blood pressure and morbidity. Epidemiologists and physicians have tended to concentrate on mortality. Perhaps that is why possible associations between fatigue and low blood pressure have been rather neglected.

We thank Professor Geoffrey Rose, Dr Lucy Carpenter, Dr Margaret Whichelow, and Dr Eurof Walters for advice. SW is supported by a Wellcome training fellowship in epidemiology.

1 Pemberton J. Does constitutional hypotension exist? Br Med J 1989;298: $60-2$.

2 Payer L. Medicine and culture: varieties of treatment in the United States, England, West Germany and France. New York: Henry Holt, 1988

3 O'Brien B. Patterns of European diagnoses and prescribing. London: Office of Health Economics, 1984

4 Beevers D. Overprescribing. Br Med f 1989;299:1284.

5 Robbins J, Korda H, Shapiro M. Treatment for a non-disease: the case of low blood pressure. Social Science and Medicine 1982;16:27-33.

6 Dally J. Low blood pressure: its causes and significance. London: Heinemann, 1928.

Friedlander A. Clinical types of hypotension. JAMA 1924;83:167-71.

8 Ayman D, Pratt J. Nature of symptoms associated with essential hypertension. Arch Intern. Med 1931;47:676-87.

9 Robinson S. Hypotension: the ideal normal blood pressure. $N$ Engl $f$ Med 1940;233:407-16.

10 Engleman $\mathrm{K}$, Braunwald $\mathrm{E}$. Hypotension and the shock syndrome. In: Petersdorfer R, Adams R, Braunwald E, Isselbacher K, Martin J, Wilson J, eds. Harrison's principles of internal medicine. 10th ed. New York: McGraw Hill, 1983:174.

11 Swales J. Clinical hypertension. London: Chapman and Hall, 1979:83-8.

12 Cruickshank J. Coronary flow reserve and the J curve relation between diastolic blood pressure and myocardial infarction. Br Med $\mathcal{f}$ 1988;297: 1227-30.

13 Cox B, Blaxter M, Buckle A, et al. The health and lifestyle survey. London: Health Promotion Research Trust, 1987.

14 Goldberg D. The detection of psychiatric illness by questionnaire. London: Oxford University Press, 1972.

15 Blaxter M. Sample and data collection. In: Cox B, Blaxter M, Buckle A, et al. The health and lifestyle survey. London: Health Promotion Research Trust, 1987:1-3.

16 Goodchild $M$, Duncan-Jones $P$. Chronicity and the general health questionnaire. Br f Psychiatry 1985;146:56-61.

17 Huppert F, Gore $M$, Elliot B. The value of an improved scoring system (CGHQ) for the general health questionnaire in a representative British ample. Pyschol Med 1988;18:1001-6.

8 Chen $M$. The epidemiology of self perceived fatigue among adults. Prev Med 1986;15:74-81

19 Wessely S. The epidemiology of fatigue: evidence from a large UK national survey [MSc Thesis]. London: London School of Hygiene and Tropical Medicine, $1989.62 \mathrm{pp}$

20 Goldberg E, Comstock G, Graves C. Psychosocial factors and blood pressure Psychol Med 1980;10:243-55.

21 Mann A. Hypertension: psychological aspects and diagnostic impact in a clinical trial. Psychol Med [Mono Suppl] 1984;5:1-35.

22 Blumhagen D. Hyper-tension: a folk illness with a medical name. Culture, Medicine and Psychiatry 1980:4:197-227.

23 Standgaard S. Autoregulation of cerebral blood flow in hypertensive patients. Circulation 1976:53:720-7.

24 Meador C. Art and science of non-disease. N Engl F Med 1965;272:92-5

(Accepted 22 fune 1990) 